\title{
Problem-Solving of Semiconductor Probe Card Using TRIZ and Quality Control (QC) Story
}

\author{
Yong Mun Jeon ${ }^{1}$, Yong Won Song ${ }^{2}$, Kyung Mo Hong ${ }^{3}$ \\ ${ }^{1}$ Engineer, 17336 SK Hynix Company, Republic of Korea, ymjun99@gmail.com \\ ${ }^{2}$ Professor, 15073 Korea Polytecic University, Republic of Korea, ywsong@kpu.ac.kr \\ ${ }^{3}$ Engineer, 17336 SK Hynix Company, Republic of Korea, crusader0120@naver.com
}

Corresponding author: Yong Mun Jeon

\begin{abstract}
In the era of the Fourth Industrial Revolution, semiconductors are among the main components in advanced technologies. It leads to the development of premium products with low power, high capacity, high performance, and high quality. Nevertheless, smartization and mobilization of IT devices require more advanced miniaturization characteristics among semiconductors, and operation testing ultra-high density wafers need to be study. The probe card, which is a key device for inspecting the operation of semiconductors and facilities that perform the final wafer testing of the fab (i.e., semiconductor fabrication), increases the total number of probes in order to cope with the micro process. The latter causes complex issues in the probe card inspection process. In this study, the set time and temperature change graph of the probe card during the Quality Control (QC) Story process, and the ratio of each item during the preheating process of the probe card were expressed in a Pareto-chart. The main improvement shown in the Pareto-chart was the application of 40 invention principles to define the Idea Final Results (IFR) using the TRIZ (Teoriya Resheniya Izobretatelskikh Zadatch) law of technological evolution and to study solutions that could minimize the effect of probe temperature on the probe card. Since the problem that occurs in the semiconductor probe card is complex, this study investigates the fusion method of QC Story and TRIZ, a famous problem solving method, to solve a real problem. The main result of this study is to improves the probe offset by achieving the probe temperature target ($10.0^{\circ} \mathrm{C}$ ) of the probe card. This enhances the probe card setup time by $27.43 \%$ and the standard deviation by 10.9 minutes, improving productivity and quality.
\end{abstract}

Keywords: QC Story, TRIZ, Probe Card, Semiconductor

\section{Introduction}

In recent years, semiconductors have been gaining attention as a major component for smart devices, artificial intelligence, 5G technology, Internet of Things (IoT), and vehicles. The importance of miniaturization of semiconductors is increasing as they are inserted in palm-sized mobile devices and wearable devices. According to customers' miniaturization requirements, the average demonstrating integration is as follows: (a) $100 \mathrm{~mm} 2$ in 2010, (b) $62 \mathrm{~mm} 2$ in 2012, (c) $38 \mathrm{~mm} 2$ in 2015, (d) $18 \mathrm{~mm} 2$ in 2016, and (e) $8 \mathrm{~mm} 2$ in 2017[1][2].

After reviewing the environmental changes for semiconductor equipment, integrated circuit technology has been developed. In addition, memory devices are being used in products that consume less power. As a result, the complexity of the devices constituting a semiconductor component greatly

Received: September 24, 2020; 1st Review Result: November 12, 2020; 2nd Review Result: December 28, 2020 Accepted: January 25, 2021 
increased, and the equipment has been improved to test many chipsets at a time to enhance productivity.

To cope with this technological requirement, the overall size of the probe card as well as the number of probes have increased. The total change in the number of probes shows the following trend: (a) 16,000 in 2010, (b) 32,000 in 2012, (c) 41,000 in 2015, (d) 66,000 in 2016, and (e) 10,000 in 2017 [3].

In addition to the environmental change of equipment and probe cards, as the multi-variety production system progresses, the equipment, products, and probe cards are combined to operate in the wafer testing process. To deal with various problems in the fine process, it was neccessary to find a convergent problem-solving method of QC Story and TRIZ.

The QC Story is a tool of Total Quality Management (TQM) to systematically solve problems. It is based on the principles of Plan-Do-Check-Action (PDCA) and provides a full story to complete the stepby-step solution.

The abbreviation TRIZ is derived from Russian words "Teoriya Resheniya Izobretatelskikh Zadatch", which stands for "Theory of Inventive Problem Solving". It is a well-established system of tools for innovative problem solving, idea generation, failure analysis, and prediction[4].

Since the field of semiconductor process quality control has the best capabilities, the data can be used to easily identify problems that are hindering manufacturing. To solve this, a combination of QC story and TRIZ is used. The QC Story is a solution process that allows anyone to easily understand, perform basic analysis, and develop PDCAs using seven data-driven QC tools. The TRIZ has the unique power to extract problem-solving ideas through 40 invention principles and separation principles by defining contradictions and Idea Final Results for problems[5]. Therefore, the fusion of the two technologies can achieve a synergy of ideal problem solving. It is also advisable to add the six sigma technique, but it lacks samples for the problem situation and thus excluded in the analysis.

The following is a description of the use of the tool according to the QC Story [Table 1] and TRIZ [Table 2].

[Table 1] QC Tools and QC Story in Relation with PDCA Cycle[6]

\begin{tabular}{|c|l|c|}
\hline PDCA Cycle & \multicolumn{1}{|c|}{ QC Story Formula } & QC Tools \\
\hline \multirow{4}{*}{ Plan } & Introduction of the cross functional team & Process Mapping \\
\cline { 2 - 3 } & Reason for selecting the theme & Bar graph, Radar chart \\
\cline { 2 - 3 } & Current (original) situation analysis & Pareto diagram, Histogram \\
\cline { 2 - 3 } & Goal setting & Line graph \\
\cline { 2 - 3 } & Activity plan & Gantt chart \\
\cline { 2 - 3 } & Analysis of causes of the problem & Fishbone diagram, Scatter diagram \\
\hline \multirow{2}{*}{ Do } & Measures examined and implemented & 5W2H \\
\hline \multirow{2}{*}{ Check } & Checking of results & Control charts \\
\hline \multirow{2}{*}{ Action } & Standardization and control & Control chart, Check sheet \\
\cline { 2 - 3 } & Future plan to solve another problem & 5W2H \\
\hline
\end{tabular}

The QC tools can be described as follows:

1) a flow-chart evaluates the solution model for a given problem using different types of boxes and arrows connecting them.

2) a bar graph contains two axes - one shows the specific category being compared and the other shows the measured values.

3) a radar chart is a useful way to display multivariate observations with multiple variables.

4) a pareto diagram arranges information in a way that set priorities for process improvement.

5) a histogram presents what data looks like by dividing the entire range of values into a series of intervals and then counting the number of values that fall into it.

6) a gantt chart is a type of bar chart showing a project schedule. The chart lists what to do on the vertical axis and the time interval on the horizontal axis. 
7) a fishbone diagram analyzes (in successive layers of detail) the root causes that could potentially contribute to a particular effect.

8) a scatter diagram identifies the type of relationship between the two quantitative variables[7].

9) a check sheet is used to provide a structured method of collecting quality-related data as a datadriven means for evaluating the process or as an input to other analyses.

10) a control chart is a graphic representation for statistical process monitoring.

[Table 2] TRIZ Tools and TRIZ in Relation with Step

\begin{tabular}{|c|c|c|}
\hline Cycle & Formula & TRIZ Tools \\
\hline 0-Step & Project Preliminary Survey Questions & $\begin{array}{l}\text { Micro Analysis, } 9 \text { Window, Cause } \\
\text { effect chain analysis, Trimming }\end{array}$ \\
\hline \multirow[b]{2}{*}{1 Step } & Define technical contradictions. & \multirow{2}{*}{$\begin{array}{c}\text { Technical Contradiction, } \\
\text { A functional diagram, } \\
\text { Field }\end{array}$} \\
\hline & $\begin{array}{l}\text { The technical contradiction (TC-1) and technical } \\
\text { contradiction (TC-2) are schematically illustrated. }\end{array}$ & \\
\hline 2-Step & $\begin{array}{l}\text { The operation time (OT) and operation zone (OZ) are } \\
\text { defined. }\end{array}$ & Field \\
\hline 3-Step & $\begin{array}{l}\text { Physical Contradiction Definition and Ideality and IFR } \\
\text { definition. }\end{array}$ & $\begin{array}{l}\text { Physical Contradiction, } \\
\text { Micro Analysis, Field }\end{array}$ \\
\hline 4-Step & Resource utilization & \\
\hline 5-Step & Use of knowledge base & Field \\
\hline 6-Step & Transformation or reconstruction of the problem & Micro Analysis \\
\hline 7-Step & $\begin{array}{l}\text { Review and elimination of the principle of physical } \\
\text { contradiction }\end{array}$ & Search Patent \\
\hline 8-Step & Use of the obtained solution & Function oriented search(FOS) \\
\hline 9-Step & Analyze the path of the solution & \\
\hline
\end{tabular}

The TRIZ Tools include:

1) the physical contradiction where there is only one variable, and the characteristics of the variable should and should not appear in the final form.

2) the separation principles, which are method of generating ideas using temporal separation, spatial separation, condition separation, partial separation, and total separation to resolve physical contradictions.

3) a technical contradiction, which is a technique that solves a problem in which one trait improves and the other deteriorates as the problem improves.

4) the 40 invention principles, which create ideas as a way to solve technical contradictions. The principles include segmentation, separation, local quality, symmetry change, merging, universality, nested doll, weight compensation, preliminary counteraction, preliminary action, beforehand compensation, equipotentiality, the other way round, spheroidality - curvature, dynamics, partial or excessive actions, another dimension, mechanical vibration, periodic action, continuity of useful action, skipping, blessing in disguise or turn lemons into lemonade, feedback, intermediary, self-service, copying, cheap short-living objects, mechanics substitution, pneumatics and hydraulics, flexible shells and thin films, porous materials, color changes, homogeneity, discarding and recovering, parameter changes, phase transitions, thermal expansion, strong oxidants, inert atmosphere, and composite materials.

5) the cause-effect chain analysis, which is a technique of finding contradictions by analyzing useful and harmful results through the causal relationship of a problem.

6) a functional diagram, which is the result of applying action to the target.

7) the FOS (function oriented search), in which, when a problem occurs, we generalize the problem and benchmark the best solution to the problem situation.

8) a field, which is the Idea derivation with the MATCEMS (Machine, Acusto, Temperature, Chemical, Electronic, Magnetic, Software) field. 
9) the nine window, where the past/future situations are drawn around the present, and higher-level systems/sub-systems are expressed accordingly.

10) a trimming, which remove parts with high ideality.

11) the micro analysis, which create a little people model and at least draw a small situation.

The QC Story and TRIZ have their own processes. The QC Story is used familiarly through ongoing group activities, and the TRIZ can only be understood by those who have completed the training and submitted the assignments. Therefore, in this paper, an overall analysis was performed through the QC Story, and the process of deriving ideas for solving creative problems was solved in parallel with the TRIZ methodology.

Initially, the process involves designing and developing the circuit on a wafer through various processes of fabrication, followed by wearing the circular silicon wafer; then, in the wafer testing process, the circuit quality of the finished wafer is examined. In the final stage, the product package is inspected and after the module inspection, the product is shipped.

The wafer testing process consists of wafer movement, Electrically Parametric Measurement (EPM) testing, burn-in testing, high and low temperature testing, quality inspection, and shipping process. During the basic test, an inspection of abnormal circuit quality/quantity is conducted. In addition, during the burn-in test, quality/quantity is inspected after high temperature voltage is applied. The high and low temperature testing process is used to test the electrical properties. Finally, in the shipping process, the quality/quantity inspection of the chip compliance is performed. The main management items for all processes are the yield curve control, foreign material management, non-conformity of probe position, and scratch management[8].

From the basic to the high and low temperature tests, the inspection facility consists of a test and a wafer transfer facility. The test facility creates and supplies the power, timing, pattern, power clamp, driver channel, and input/output (I/O) channels required for the wafer operation circuit; the generated signals are transmitted to the test head through the interface cable. The top of the probe card is engaged with the test head, and the signal received from the test equipment is transmitted. The wafer transfer facility, which is composed of a pair, controls the high/low temperature environment, and loads the wafer to align it in an optimal state[9].

Finally, each signal is transmitted to the probe located at the bottom of the probe card through channel expansion operations. The contact must be performed while being accurately aligned with the wafer pad.
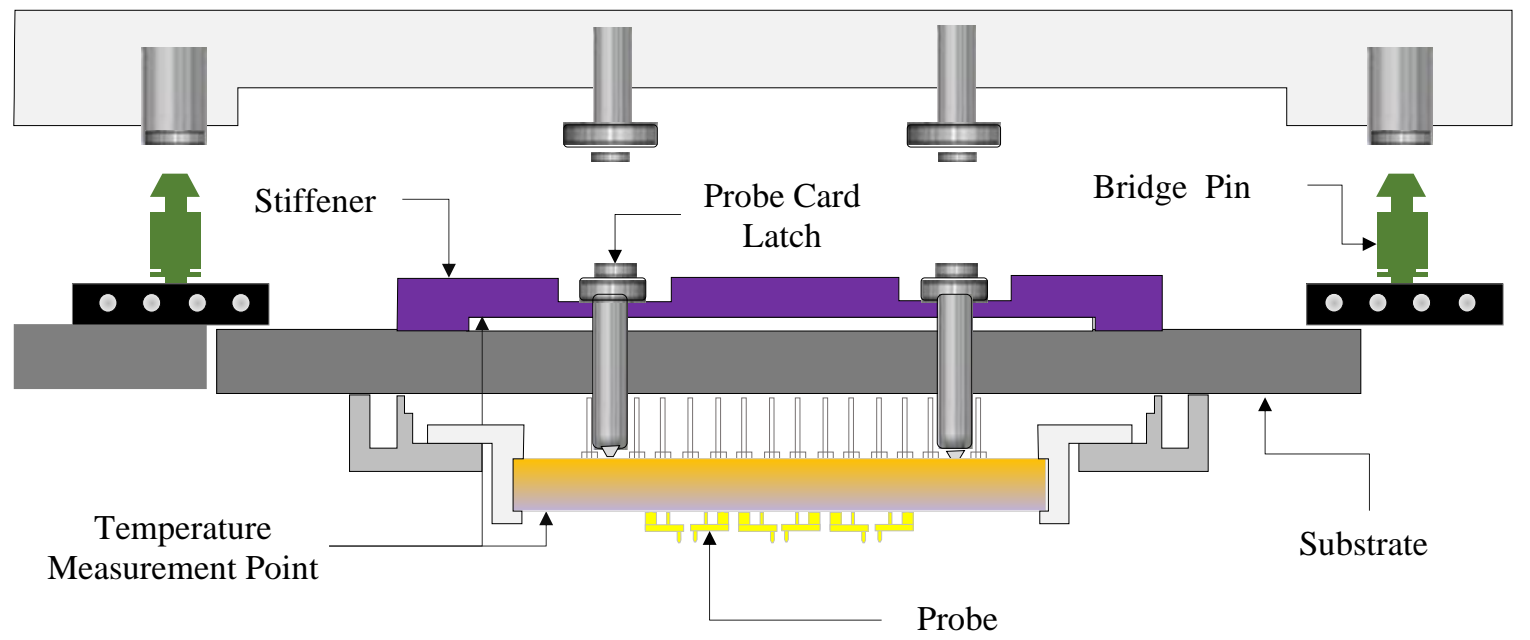

[Fig. 1] Partial Structure of the Test Head and the Configuration of the Probe Card 
The probe card is installed in the wafer transfer equipment. It is the main means for determining the normality/abnormality of the completed wafer chipset while transmitting and receiving electrical signals by contacting the probe with the wafer pad.

[Fig. 1] explains some of the partial structures of the test head and the main configuration contents of the probe card. The prober station, which controls the accuracy of the probe card, should be set to low temperature $\left(-40^{\circ} \mathrm{C}\right)$ or high temperature $\left(95^{\circ} \mathrm{C}\right)$. Once the temperature is set, it remains constant until the inspection is completed. To check the probe offset of the probe card, the thermal expansion test of the probe is checked as well. The measurement point of the temperature was defined as the lower parts of the ceramic and the stiffener; subsequently, the measurement was performed[10].

\section{Problem Solving Process}

In the process of solving the problem, TRIZ's technical contradictions were incorporated into the QC story to define the IFR for the problem, and 40 invention principles were used to derive and apply the final idea. This research model can clearly and simply proceed with the development of a complex ideaderived process after creating a Fishbone Diagram of the the QC Story. [Table 2] presents the technical contradictions and 40 invention principles constituting the research model.

The paper is a model to study how to efficiently combine the idea submission and problem solving required for semiconductor process improvement in the improvement process.

[QC Story Process]

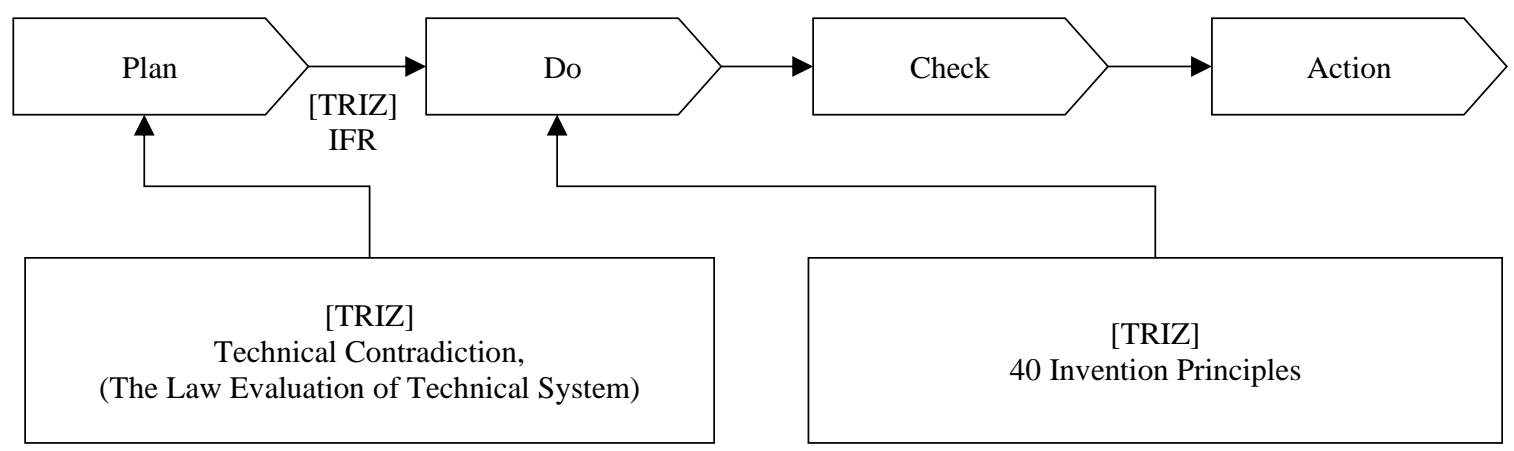

[Fig. 2] Research Methodology Process

\subsection{Problem Situation}

After installing the probe card in the facility, the setup was performed to manage time (in minutes) until the start of wafer testing. The facility was divided into facility group A and facility group B. The results of monthly reviews are presented in [Table 3]. The setup time increased in facility group B compared to facility group A. In addition, the occurrence of wafer test misalignment (WTMA) in facility group B increased significantly.

[Table 3] Number of WTMA Occurrences per Facility and Setup Time

\begin{tabular}{|c|c|c|c|c|}
\hline \multirow{2}{*}{ Month } & \multicolumn{2}{|c|}{ Item } & Number of WTMA Occurrences & \multicolumn{2}{c|}{ Set-up Time (Preheating related) } \\
\cline { 2 - 5 } & Facility Group A & Facility Group B & Facility Group A & Facility Group B \\
\hline October & 3 & 26 & 47.4 & 68.5 \\
\hline November & 5 & 24 & 47.2 & 65.2 \\
\hline December & 4 & 26 & 48.5 & 69.5 \\
\hline
\end{tabular}


In this case, the WTMA refers to a phenomenon in which the probe marks are located outside the size of the pad (i.e., approximately $60 \mu \mathrm{m} \times 60 \mu \mathrm{m}$ ) in the wafer chipset (Die), which is a criterion for determining the non-conforming chipset.

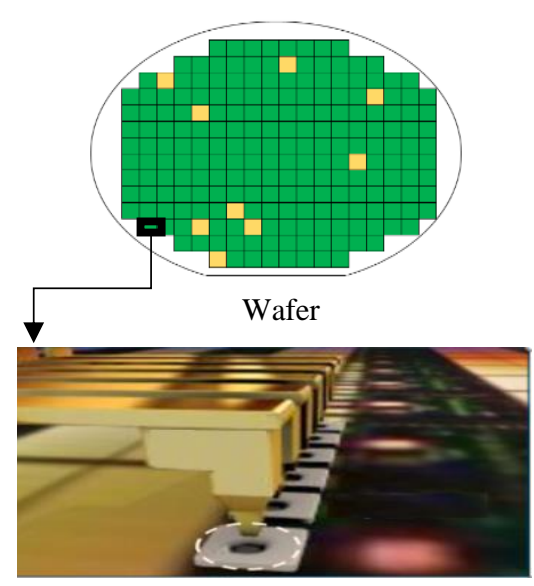

Conformed Chipset (Pad)

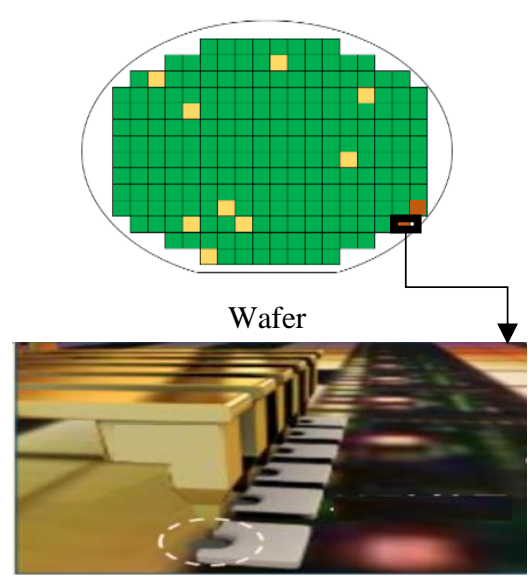

Nonconformed Chipset (Pad)

[Fig. 3] Conformity and Nonconformity of Chipset (Pad)

This type of problem occurred at the beginning of the setup rather than during wafer testing. In order to analyze it, the setup process was created as presented in [Fig. 4].

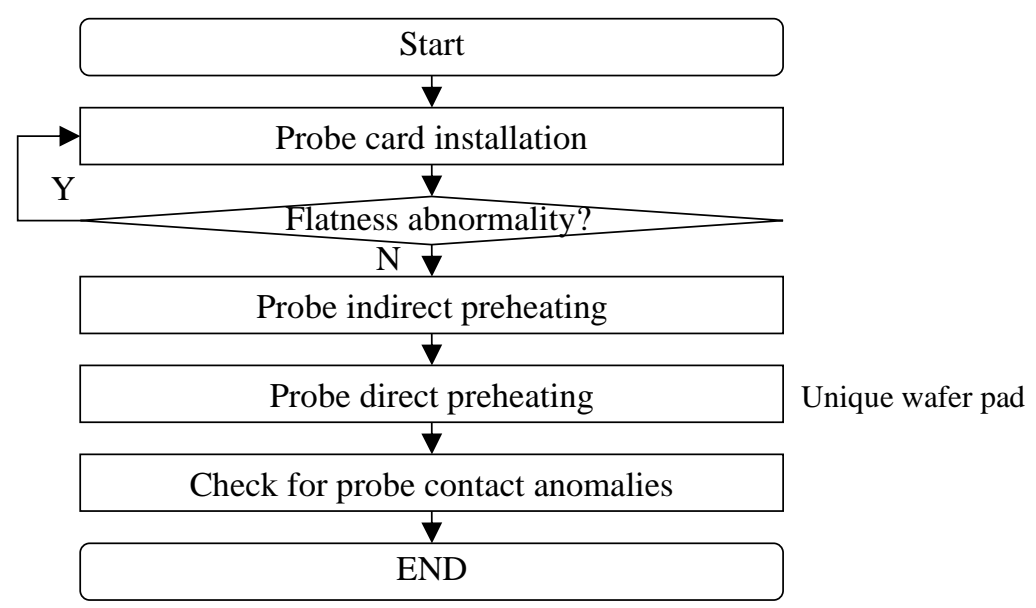

[Fig. 4] Setup Process

Based on the process depicted in [Fig. 4], it was investigated that the WTMA occurrence occupied $86 \%$ when the probe was directly preheated. In this case, it implies that the indirect preheating is insufficient. However, in the case of Facility Group B, the WTMA continues to occur despite the more indirect preheating compared to Facility Group A. As a WTMA phenomenon, it spread out to the outside of the wafer and became a probe. This is a phenomenon that occurs when testing at low temperatures; therefore, it is necessary to check the probe card temperature distribution at these temperatures[11].

For verification, a temperature measurement sensor was attached to the probe card; the temperature change up to the probe optimization time was checked for each section according to the setup, and the variation in temperature is shown in [Fig. 5].

In [Fig. 5], point 5 is the testing starting point of Facility Group B. This proves that it takes a significant amount of time compared to Facility Group A, and it can be confirmed that there is a remarkable difference even when the temperature drops. From the results of this experiment, it was confirmed that the WTMA occurrences and the setup time increased due to the difference in the thermal deformation of the probe card in Facility Group B compared to Facility Group A. 


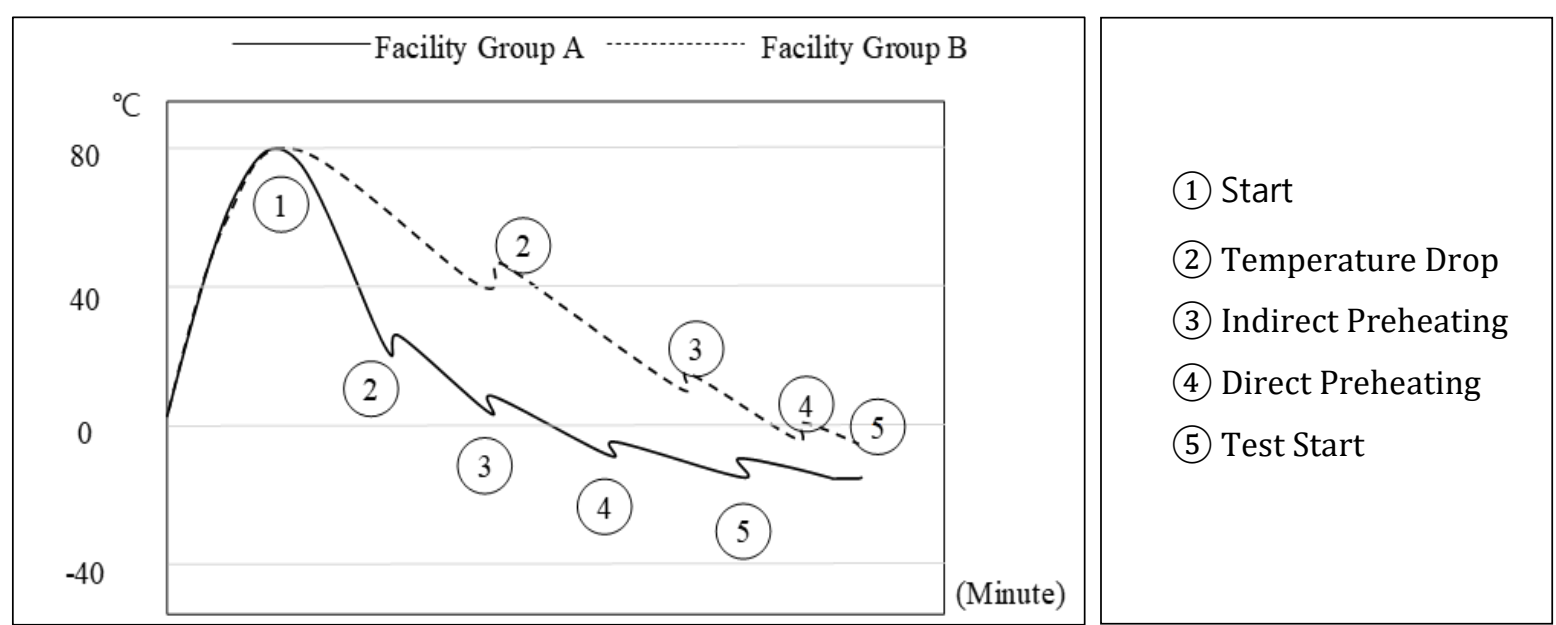

[Fig. 5] Temperature Distribution According to the Setup Process for each Facility Group

In [Table 4], the results indicated that the low temperature test condition requires the temperature of the probe card's measurement sensor to remain below $-10^{\circ} \mathrm{C}$. However, the insufficient temperatures provided to the probe card caused deformation of the pre-applied offset, which led to direct preheating at the incorrect probe position. Therefore, as the position of the probe card was deformed on the wafer pad, an improvement was needed in this area.

[Table 4] Probe Card Setup with Low-Temperature Change

\begin{tabular}{|c|c|c|c|c|}
\hline Point & Interval Item & Facility Group A & Facility Group B & Notes \\
\hline (1) to (2) & Temperature Drop & 22.5 & 39.4 & - \\
\hline (2) to (3) & Indirect Preheating & 4.5 & 10.3 & - \\
\hline (3) to (4) & Direct Preheating & -10.1 & $-\mathbf{5 . 7}$ & Problem Start \\
\hline (4) to (5) & Test Start & -15.3 & -10.9 & - \\
\hline & Total & - & - & \\
\hline
\end{tabular}

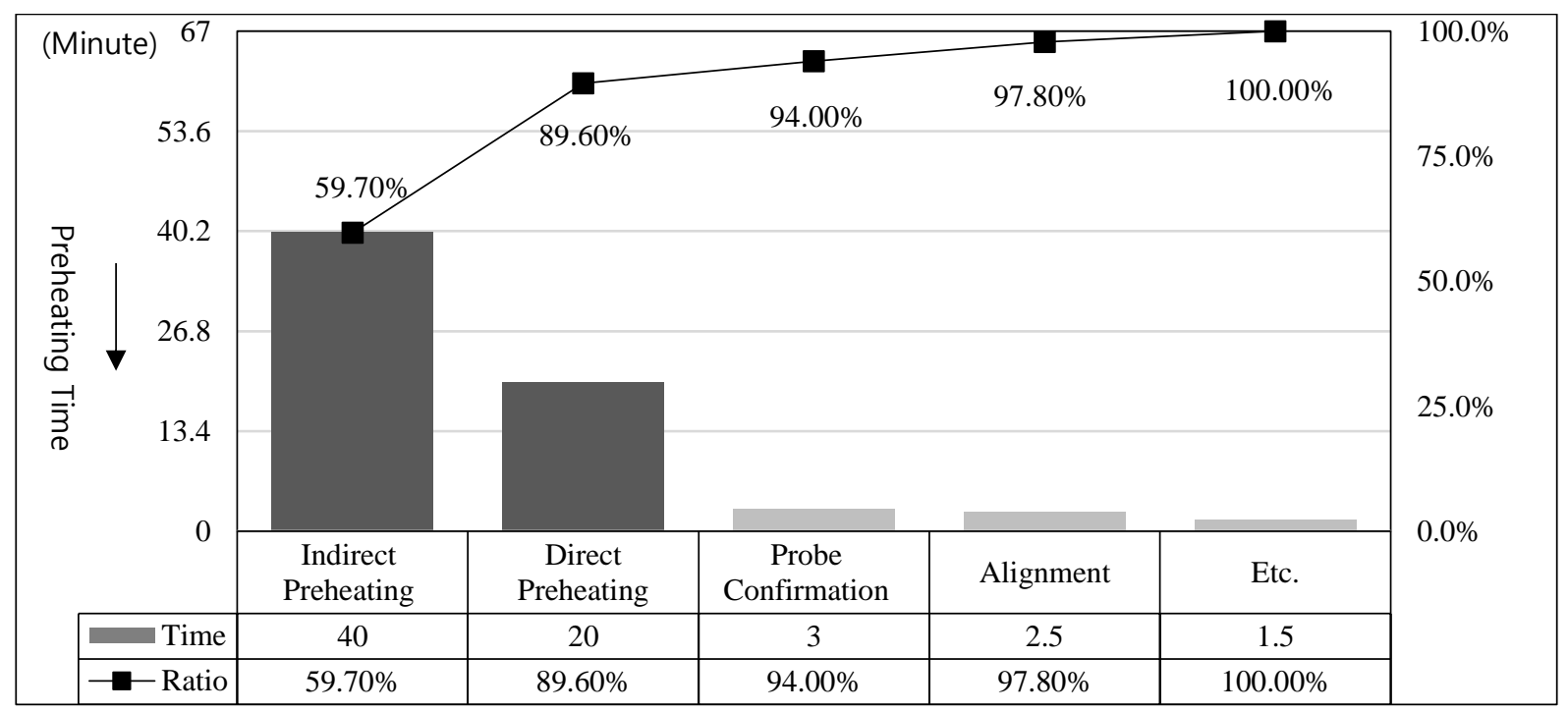

[Fig. 6] Preheating Process Pareto Diagram

In [Fig. 6], much time is required in indirect and direct preheating processes. For this reason, the indirect and direct preheating methods are illustrated in [Fig. 7]. 

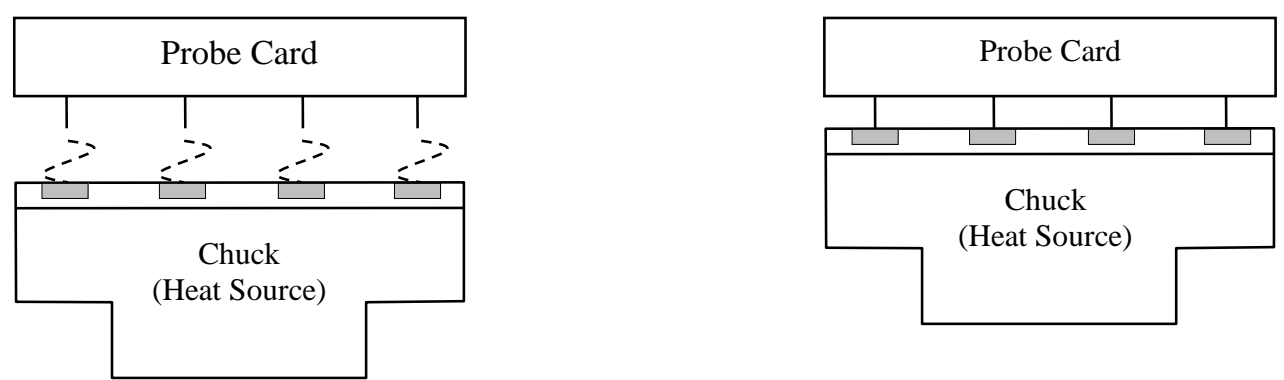

[Fig. 7] Indirect (left) and Direct (right) Preheating Methods

Since the test conditions must be accurately probed on the wafer pads at high and low temperatures, the indirect preheating method is optimized and the overall expansion of the probe card is stabilized through the direct preheating method.

Given that the indirect preheating method transfers heat from the prober system through the wafer away from the probe card, the probe card temperature graph follows a logarithmic distribution; hence, the probe expansion cannot be maximized. Therefore, through the direct preheating method, the expansion of the probe card is continuously increased to find a condition where it will no longer be expanded.

However, under the condition of Facility Group B, where the indirect preheating is doubled, there is a quality concern to be applied by reducing the time. Thus, the probe card required thermal correction and it was a typical technical contradiction.

\subsection{Problem Analysis}

[Fig. 8] shows the necessary items for the law of technological system evolution. The Ideal Final Result (IFR) is one of the tools used in TRIZ's problem definition phase. It is like the final state to fix the current problem.

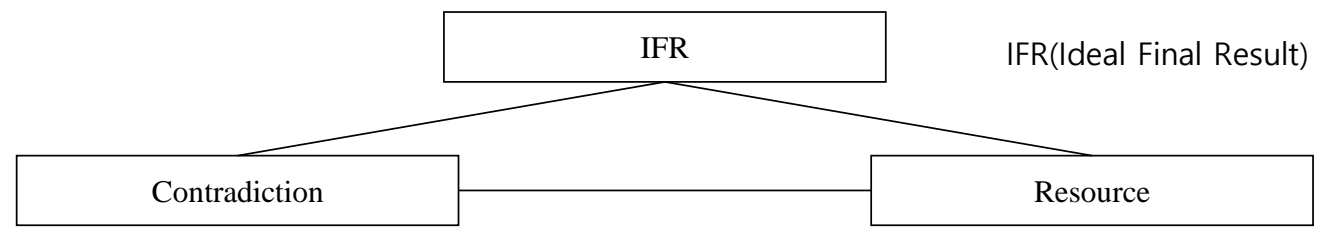

[Fig. 8] The Law of Evolution of Technical Systems

The technical contradiction, IFR, and resources are schematically depicted in [Fig. 9].

\begin{tabular}{|c|c|c|c|}
\hline \multicolumn{2}{|c|}{ Technology Contradiction } & IFR \\
\hline $\begin{array}{c}\text { If indirect heating is } \\
\text { applied }\end{array}$ & \begin{tabular}{c|c|c|}
\hline Preheat without contact \\
Minimize quality (Scratch)
\end{tabular} & Increase preheating time & $\begin{array}{c}\text { Fast preheating should be } \\
\text { applied without quality impact. }\end{array}$ \\
\hline \begin{tabular}{c|c|c|} 
If indirect heating is not \\
applied
\end{tabular} & $\begin{array}{c}\text { Reduce preheating time } \\
\text { (scratch, push) }\end{array}$ & $\begin{array}{c}\text { Quality (scratch, push) } \\
\text { abnormality }\end{array}$ & $\begin{array}{c}\text { Even if the preheating time is } \\
\text { reduced, there should be no } \\
\text { abnormality in quality. }\end{array}$ \\
\hline Resource & \multicolumn{2}{|c|}{ Cleaning (Media1, Media 2, Media 3), Media 4, Media 5, probe card, air } \\
\hline
\end{tabular}

[Fig. 9] Description of Technology Contradiction, IFR and Resources

By checking the 39 parameters of the TRIZ technical system, it was confirmed that there is no recommended invention principle as a result of substituting the property (manufacturing precision (29)) and deteriorating property (operating time of immobile objects (16)) into the contradiction matrix[12]. 
As a result, the brainstorming method involving the 40 invention principles was used to gather many opinions from the field. As shown in [Table 5], ideas in the 40 principles of invention items were derived through technology contradiction, IFR, and resource definition.

[Table 5] Derivation and Review of the ideas of 40 Inventive Principles

\begin{tabular}{|c|c|c|c|}
\hline Number & Item & Idea & Review \\
\hline 2 & Extraction & Apply direct preheating only. & - \\
\hline 3 & Local quality & Change the preheating height differently. & - \\
\hline 5 & Merger & Make the direct and indirect preheating space the same. & - \\
\hline 6 & Multipurpose & Other media function as preheating. & O \\
\hline 9 & Preliminary action & Preheat with a heater. & - \\
\hline 15 & Increase dynamic properties & Apply step-by-step preheating. & O \\
\hline 16 & Excessive or insufficient & Reduce the preheating time. & - \\
\hline 19 & Cyclic action & Divide the preheating. & O \\
\hline 23 & Feedback & Notification by attaching a temperature sensor. & - \\
\hline 24 & Use of media & Use surrounding media instead of production wafers. & O \\
\hline 27 & Short life & Develop heater function. & - \\
\hline 33 & Homogeneity & Use the same media as the production wafer. & O \\
\hline
\end{tabular}

By reviewing the ideas of the five items derived through the 40 invention principles, the item for use of media and application of step-by-step preheating is established and presented in [Table 6].

[Table 6] Establishment of the 40 Inventive Principles Idea

\begin{tabular}{|c|c|c|c|}
\hline Number & Inventive Principle & Idea & Result \\
\hline 24 & Use of Media & Use surrounding media. & \multirow{3}{*}{ Usage of media } \\
\hline 33 & Homogeneity & Use the same media as the production wafer. & \\
\hline 6 & Multipurpose & Other media function as preheating. & \\
\hline 15 & Increase dynamic properties & Apply step-by-step preheating. & \multirow{2}{*}{ Application of step by step preheating } \\
\hline 19 & Cyclic action & Divide the preheating. & \\
\hline
\end{tabular}

Therefore, the final opinion was improved with two items: the use of media and the application of step-by-step preheating that are explained below.

\subsubsection{Use of Media}

The common item of ideas derived by using the invention principles of use of media(24), homogeneity (33), and multipurpose (6) was the use of media. It was also reviewed in the general context of media use.

In summary, the media used in the facility is shown in [Table 7] and it was assessed by charting based on economy, technology, production (workability); media 5 with high score in surrounding resources utilization and production was used after precise analysis of the expected problems.

[Table 7] Analysis of Expected Media Use Problems

\begin{tabular}{|c|c|c|c|c|c|c|}
\hline Medium & Surrounding Resources & Expected Problems & Economy & Technology & Production & Total \\
\hline Media 1 & - & - & 1 & 3 & 1 & 5 \\
\hline Media 2 & - & - & 5 & 3 & 1 & 9 \\
\hline Media 3 & Y & - & 3 & 3 & 3 & 9 \\
\hline Media 4 & Y & - & 3 & 3 & 3 & 9 \\
\hline Media 5 & Y & - & $\mathbf{3}$ & $\mathbf{5}$ & $\mathbf{5}$ & $\mathbf{1 1}$ \\
\hline
\end{tabular}




\subsubsection{Application of Step-by-Step Preheating}

The common items of idea derived by utilizing the dynamic characteristic increase (15) and the cyclic action (19) invention principles will apply the step-by-step preheating process.

[Table 8] Step-by-Step Preheating Application Items

\begin{tabular}{|c|c|c|c|c|c|}
\hline \multicolumn{1}{|c|}{ Category } & \multicolumn{5}{|c|}{ Application of cyclic properties (19) } \\
\hline \multirow{4}{*}{ Increase dynamic characteristics (15) } & - & - & - & - & - \\
\cline { 2 - 6 } & - & - & - & - & - \\
\cline { 2 - 6 } & - & - & - & - & - \\
\hline
\end{tabular}

\subsection{Application of Solution}

The [Table 8] items are designed and applied so that the step-by-step preheating function can be applied to the product setup standard information. The modified contents are shown in [Fig. 10].
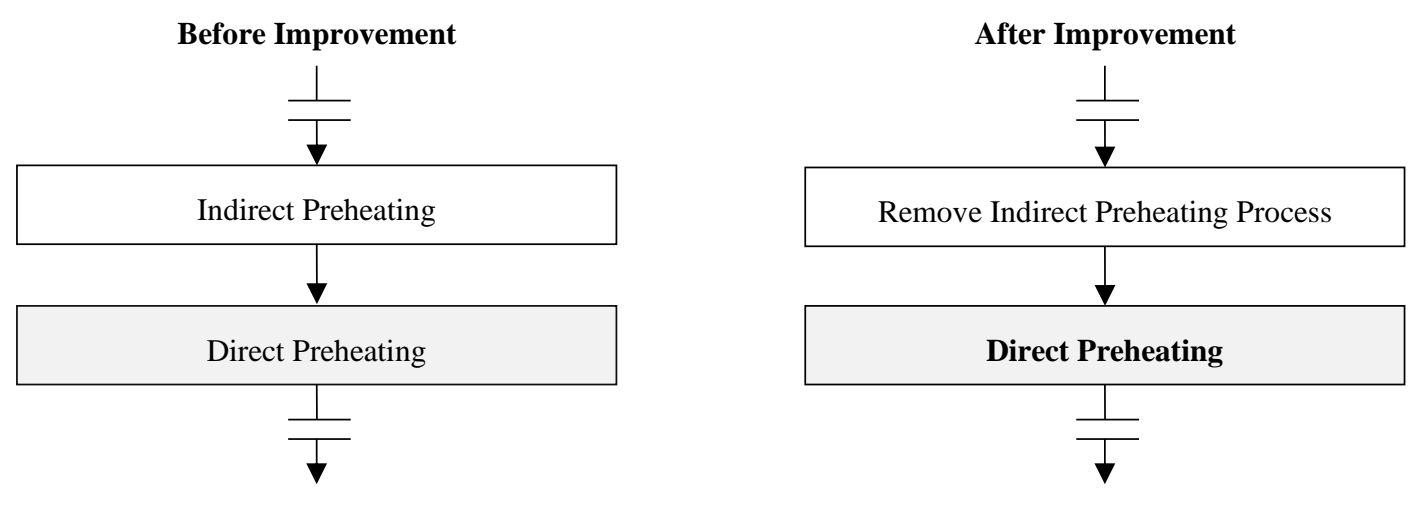

[Fig. 10] Flow Charts of Procedures Before and After Improvement

The main reason for the indirect preheating was to remove the root cause of WTMA in the wafer pad during direct preheating. However, as the conditions changed according to the environmental conditions of the probe card and the diversification of facilities, TRIZ was at the center of solving problems occurring in specific facilities. The importance of TRIZ ideas here lies in the definition of the technical contradictions and in the process of using the surrounding resources to generate the most ideal ideas.

$$
\text { Ideality }=\frac{\sum \text { Benefical Functions }}{\sum(\text { Cost }+ \text { Harmful Functions })}
$$

Here, ideality (1) is the sum of the beneficial functions performed by the system divided by the sum of the cost required to improve system performance and the harmful behavior that occurs in the system. This formula brings progress to the the problem solving steps[13][14].

\subsection{Results of the study}

As seen in [Fig. 11], the result of improvement evaluation, the management goal of $-10{ }^{\circ} \mathrm{C}$ or lower was achieved, and a stable setup was possible. It was confirmed that there was no problem through evaluating and applying the setup conditions equivalent to the Facility Group A. In addition, as the probe card target temperature was reached quickly, the probe card probe offset was optimized to solve the problem of non-conforming chipsets and improve quality.

As a result of the analysis of the setup time histogram of the entire Facility Group B's product group from the viewpoint of post-management, the application of this project contributed to the productivity 
improvement. Its average setup time based on the standard deviation improved significantly, as shown in the before and after improvement comparison in [Fig. 12].

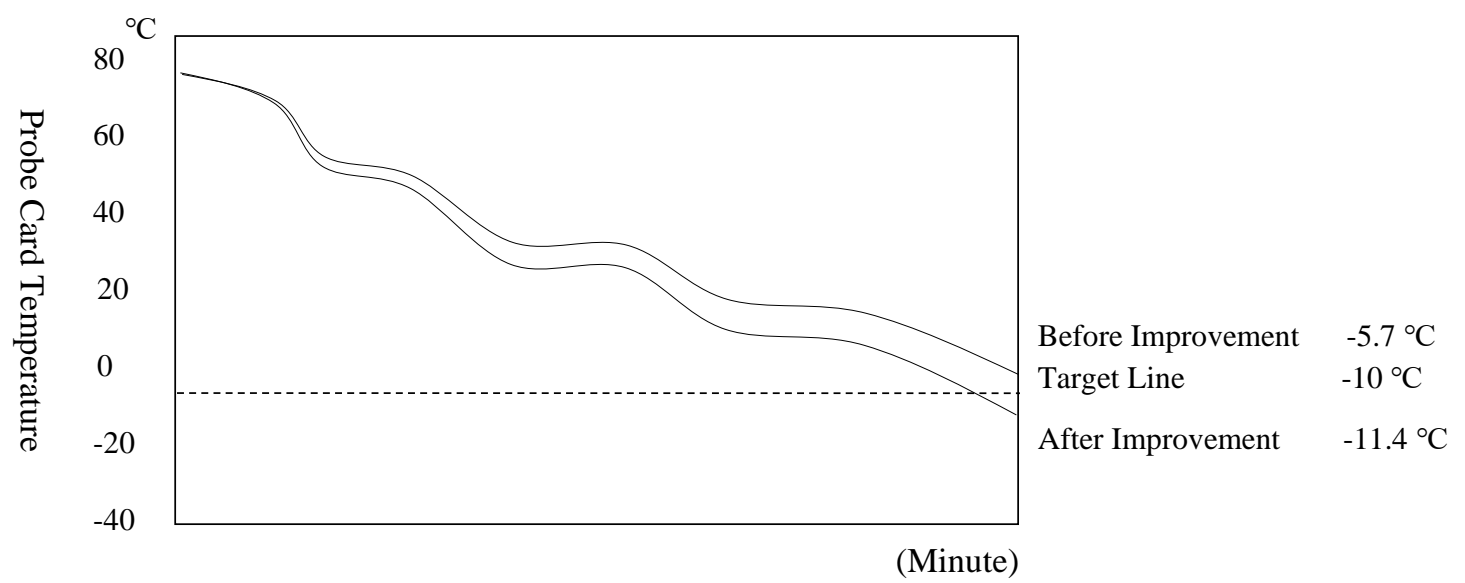

[Fig. 11] Improvement Evaluation Temperature Trend

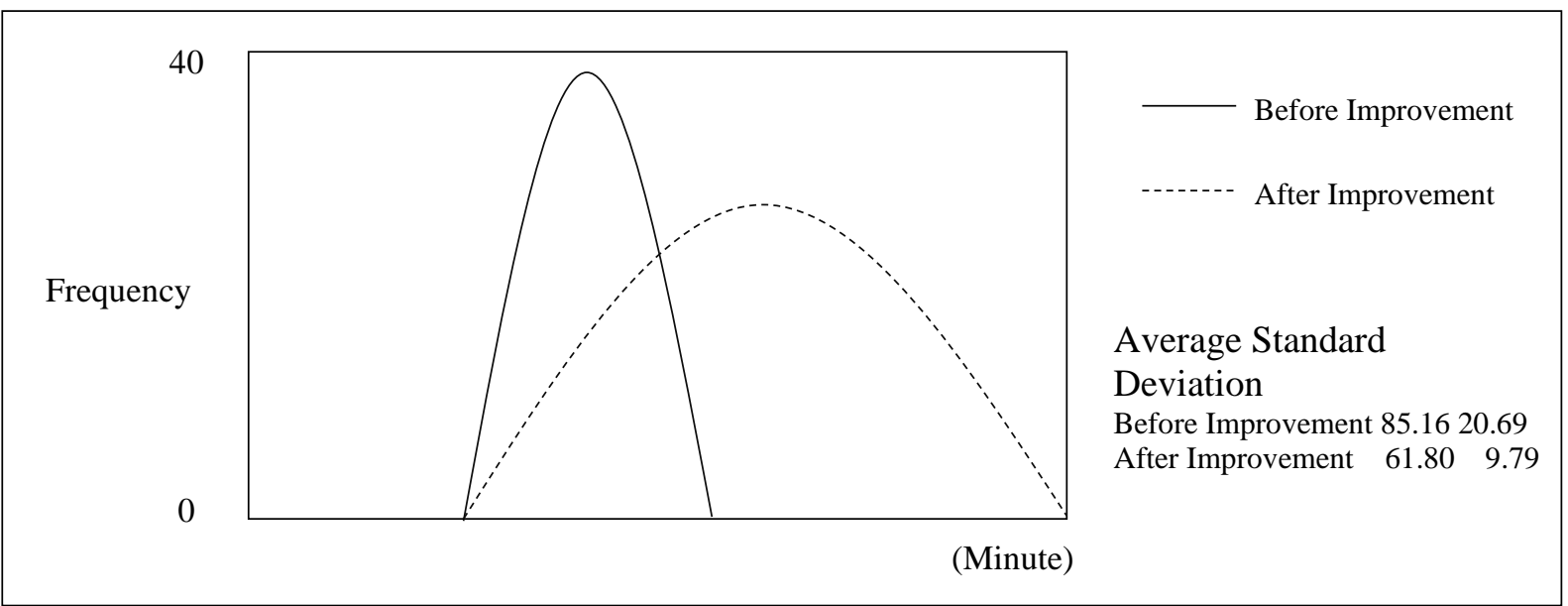

[Fig. 12] Setup Time Histogram Before and After Improvement of Facility Group B

\section{Conclusions}

Convergence methodology creates operational efficiencies because it uses QC stories to identify the importance of failures or defects. It also uses TRIZ to define the contradictions in problems, submit new ideas for improvement, and provide value in making decisions.

The following conclusions were obtained through this study.

First, the researchers shortened the installation time of the probe card and improved the proportion of non-WTMA products to improve productivity and quality.

Second, it was analyzed that some of the TRIZ techniques proposed in the fusion research model can respond to the QC Story tool.

Third, TRIZ problem solving techniques are relatively easy to complete the training and generate ideas. In this study, brainstorming was used to submit 40 invention principles ideas and come up with many ideas.

The effectiveness of the QC Story and TRIZ techniques in this study is limited to their application on solving a specific semiconductor process problem in the manufacturing industry. Also, the number of the samples used is few. These are considered as the limitations of the study. Considering that the recent TRIZ innovation is spreading to information / communication / bio / services, it is judged that research 
in various fields is necessary, and more research and problem solving are needed to establish the process.

The future plan is to combine QC Story, TRIZ, six Sigma to solve the problem and combine the strengths of the course to evaluate the research model so that even beginners can easily give directions. In addition, problems caused by various conditions in the manufacturing environment continue to occur and are undergoing a resolution process. As thermal strain and microscopic non-destructive measurement technology advances, proponents will use TRIZ to take the lead in overcoming current challenges.

\section{Acknowledgement}

This research was supported by the Basic Science Research Program through the National Research Foundation of Korea (NRF) funded by the Ministry of Education (2018R1D1A1B07049244)

\section{References}

[1] https://www.samsungsemiconstory.com/2111, Aug 28 (2019)

[2] Jae-Kyung Kim, Jon-Mo Yoon, Bong-Soo Lee, Assessment of Competitive Edge of Major Global Semiconductor Vendors for Self-Driving Solutions (Level 3 and Above)- Evaluation of Qualcomm, Intel, and Nvidia, Asia-pacific Journal of Convergent Research Interchange, (2020), Vol.6, No.10, pp.165-180, DOI : 10.47116/apjcri.2020.10.13

[3] Yong-Mun Jeon, Yong-Won Song, Solving Semiconductor Probe Card Problems Utilizing TRIZ and Data Analysis, ACTA TECHNICA NAPOCENSIS-Series: APPLIED MATHEMATICS, MECHANICS and ENGINEERING, (2020), Vol.63, No. 3S.

[4] G. S. Altshuller, TRIZ, Translator, Jo Hyeonghui, HyeonSilgwamiraesa, pp. 304, (1998)

[5] Byungho Kim, A study on the key success factors of TRIZ innovation, Dankook University, Doctoral Dissertation, (2017)

[6 H. Hailu, H. Tabuchi, H. Ezawa, K. Jilcha, T. Hailu, Minimization of Long Delivery Time of Shoe by integration of 7 QC Tools and QC Story Formula: The case of Sheba Leather PLC, International Journal of Current Research , (2018), Vol.10, No. 5, pp.68879-68895.

[7] https://en.wikipedia.org/wiki/Scatter_plot, Wikipedia.

[8] https://www.skcareersjournal.com/1203, Aug 2 (2018)

[9] Lee Eun Jung, Probe head and card structures for high-speed wafer level testing of application processor (AP) with LPDDR interface, KAIST, Master's Thesis, (2015)

[10] https://www.formfactor.com/product/probe-cards/dram/smartmatrix/, formfactor.

[11] Hwang Kyu Man, A Study on Thermal Deformation of Substrate of Probe Card for Semiconductor Wafer Test, Sungkyunkwan University, Master's Thesis, (2012)

[12] Yong Won Song, Kyung Mo Kim, Sung Hwan Kim, Creative Problem Solving Theory TRIZ, Korea Standards Association Media, (2017)

[13] Yong-Won Song, Analysis of Technology Evolution Trends for Predicting Future Technologies, Asia-pacific Journal of Convergent Research Interchange, (2020), Vol.6, No.10, pp.123-136.

[14] Chan-Woo Park, Mit-Eum Lee, Seong-Tae Lee, Yong-Won Song, Analysis of Technological Evolution for TV Displays Using S-Curves, Asia-pacific Journal of Convergent Research Interchange, (2020), Vol.6, No.10, pp.147-163. 